\title{
Anthrovision
}

Vaneasa Online Journal

\section{Editorial Anthrovision Issue 5.2}

\section{Nadine Wanono}

\section{(2) OpenEdition}

\section{Journals}

Electronic version

URL: http://journals.openedition.org/anthrovision/2970

DOI: 10.4000/anthrovision.2970

ISSN: 2198-6754

\section{Publisher}

VANEASA - Visual Anthropology Network of European Association of Social Anthropologists

\section{Electronic reference}

Nadine Wanono, «Editorial Anthrovision Issue 5.2 », Anthrovision [Online], 5.2 | 2017, Online since 31 December 2017, connection on 24 September 2020. URL : http://journals.openedition.org/ anthrovision/2970 ; DOI : https://doi.org/10.4000/anthrovision.2970

This text was automatically generated on 24 September 2020.

(C) Anthrovision 


\title{
Editorial Anthrovision Issue 5.2
}

\author{
Nadine Wanono
}

1 This special issue dedicated to photography is a particularly challenging one as the relationship between photography in the academic context of anthropological knowledge production is extremely relevant and important to the study of interactions between anthropology's visual history and contemporary issues related to identities in context of renewal traditions or to digital images, for example in Nepal, and the categorisation and stereotypical expectations linked, for example to "ecologies of belonging", to cite some of the topics discussed in this journal.

2 The overall purpose of this themed issue is to remind ourselves of the relevance of images to anthropological thought and analysis. As Edwards and Morton suggest in the introduction of their book Photography, Anthropology and History: Expanding the Frame (2009)1 "ways in which visual methods, and a consideration of photography and photographs, constitutes an increasingly important prism through which to address wider theoretical concerns within mainstream anthropology, and thus the contribution of the visual, and indeed material, to anthropological thought".

Within this perspective, this issue is especially relevant for the challenges raised by the articles, which explore the methodological complexities we have to face when we are confronted with visual representations, as creation of new space, or new identities.

We have moved on from the historical point of view noted by David Green (1984) ${ }^{2}$ "when anthropology was laying claim to scientific status...photography was ideally placed to assert its unique contribution to the new discipline", when photography was perceived to capture an accurate and objective representation of its subject.

5 These case studies presented in this issue focus on the multiple ways visual methodology can be developed during anthropological fieldwork, and how anthropologists use the photographs themselves as the methodological and analytical starting point. The articles demonstrate, from different perspectives and approaches, how both photographic practice and photographic encounters can capture the tension between anthropological concerns and fieldwork relationships, and between the production of anthropological knowledge and the mediated fieldwork. It is a way to 
open up analytical possibilities through which a deeper understanding of the anthropological project might emerge.

6 Manéli Farahmand re-examines how the Maya are portrayed in a globalised context. She focuses on the different movements seeking "indigenousness" by drawing on a New Age and holistic culture. The subjects photographed during her collaboration are tackling these issues by revolving around quests for authenticity, legitimacy and negotiation of (intra)-cultural differences.

7 In a different approach, Melanie Langpap gives us insights into the new ways, in Liechty's "non-local 'other region' has become filled to overflowing with images of other worlds, other ways of being, other 'possible lives' " (2010: 189). How does the collusion between media, politics and economics interfere and create a new space of expression and absorption? Langpap recalls Stuart Hall's argument that one of the most important elements of an image concerns the power to represent someone or something in a certain way.

Thera Mjaaland focuses specifically on participatory methodologies and their interpretation in visual anthropology and anthropology in general. How can we define participatory involvement ethically, and with what consequences for the protagonists involved in the project? Mjaaland advocates "co-photographing" and the discussions that arise from these collaborations.

Cristina Grasseni underlines the necessity of shifting our attention from technologies of beliefs to "ecologies of belongings" and the ways we are perceived by cultural stereotype which are mainly produced by ourselves. As Grasseni explains, "the main tenet of this piece is that the act of looking and categorizing self and others should be understood as a form of relational and situated learning, rather than as a problem of (facial) recognition".

10 Rasmus Rodineliussen invites us to dive with him, to share and experiment with a sensorial approach to diving, and ways of representing this touristic activity within an ecological dimension.

11 This selection of articles reminds us of the vivid and multidisciplinary debates surrounding methodologies and approaches for and from our fieldwork. They also reflect the current debates and actual difficulties we are facing with as anthropologists regarding the widespread political control in our respective institutions that are closely linked to the academic production of knowledge. Images, their productions, appropriations, circulation, emission and their reproduction themselves reflect the issues we are facing with identity, cultural singularity, ecology, and tourism.

\section{NOTES}

1. Elizabeth Edwards and Christopher Morton (eds.). Photographs, Museums, Collections: Between Art and Information. London and New York, Bloomsbury, 2015, $272 \mathrm{p}$.

2. Green, David, 1984, 'Classified Subjects: Photography and Anthropology: The Technology of Power'. Ten.8 